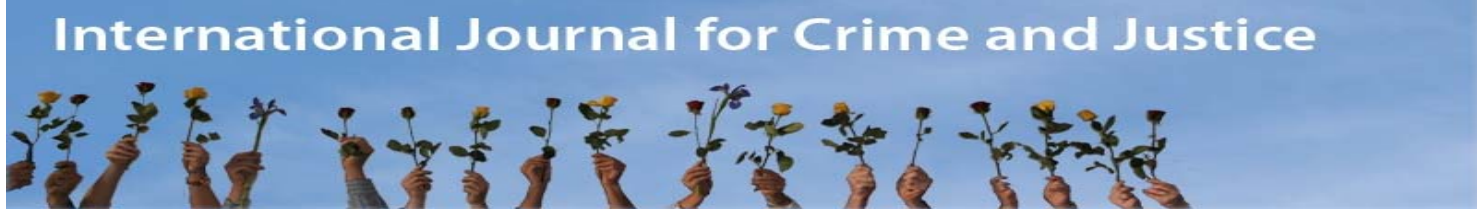

\title{
Invalidation: A Neglected Dimension of Gender-based Violence and Inequality
}

\author{
Michael Salter \\ University of Western Sydney, Sydney
}

\begin{abstract}
This article proposes that invalidation is a pervasive manifestation of gender relations as expressed through strategies of minimisation, disbelief and denial. Invalidation is embedded within interpersonal and institutionalised arrangements and interactions. It is a constitute element of gender-based violence as well as a socio-political condition that enables genderbased violence. Invalidation serves to inscribe gender relations upon the bodies of women through the mental and physical health deficits of the gender-based violence that it enables and facilitates, as well as through the denial of testimonial legitimacy and the consequent withholding of resources, support and services.
\end{abstract}

\section{Keywords}

Gender, violence, testimony, inequality, health, justice.

\section{Introduction}

Gender-based violence (GBV) is widely recognised to be one of the most serious and ongoing threats to the health of girls and women worldwide (García-Moreno et al. 2005; Heise et al. 2002; Nakray 2013). However the health burden of GBV is determined not only by prevalence and severity of such acts but also by the ways that bystanders, systems and institutions respond to the victim. A range of studies show that victims whose experiences of GBV are ignored, trivialised or disbelieved are more likely to develop trauma-related mental health problems than victims who receive care, support and validation (Cambell et al. 2001; Coker et al. 2002; Kaukinen and DeMaris 2009; Ullman 2003). Victims of GBV frequently experience invalidation and disbelief from those in the community as well as from medical and legal services, while the mental health consequences of invalidation, such as 'hysteria' and neurosis, feature prominently in hegemonic rationalisations for the dismissal of the accounts of girls and women (Campbell 2003; Warner 1996).

The paper recognises that the power to dismiss, trivialise or silence the perspective of another is not evenly distributed throughout society but rather a specific dimension of masculine privilege that has an important role to play in the perpetuation of gendered inequality. It will discuss the role of invalidation as an antecedent to and feature of GBV, emphasising the ways in which perpetrators employ invalidation as a strategy to ensure victim compliance and silence. The paper will then illustrate the ways in which the invalidating conduct of perpetrators reflects 
broader social patterns and responses to victims that result in the development of a range of mental health problems and disabilities. The final section will address the ideological implications of invalidation as a manifestation of male domination. The paper will close by discussing the implications of invalidation for those services and systems that are tasked to respond to GBV and women's mental health.

\section{Extent and impact of GBV}

There is no standard definition of GBV, also called 'gendered violence' or 'gender violence', but these terms are most commonly used to refer to acts of physical and sexual abuse by men against women as well as the interpersonal, social and political contexts that facilitate such acts. For example, Article 1 of the United Nations Declaration on the Elimination of Violence against Women (1993) defines 'violence against women' as 'Any act of gender-based violence that results in, or is likely to result in, physical, sexual or psychological harm or suffering to women, including threats of such acts, coercion or arbitrary deprivations of liberty, whether occurring in public or in private life'. Such a definition acknowledges that acts of physical and sexual violence are often contextualised within larger patterns of coercive behaviour by men, such as neglect, deprivation, psychological and emotional abuse, threats and financial control (Johnson 2008; Stark 2007). Furthermore, GBV is not limited to interpersonal relations but can be facilitated and perpetrated by state actors (such as governments, the police and the military) and by nonstate actors (such as paramilitary groups).

For the purposes of this paper, the term GBV incorporates violence against children as well as women in recognition of the linkages between child and woman abuse, including the continuum of GBV from girlhood to womanhood (for example, Kelly 1988), and the impact of violence against women upon their children (for a recent meta-analysis, see Evans et al. 2008). GBV is recognised as one of the leading causes of injury and death to women. In its 1993 World Development Report, the World Bank estimated that the impact of GBV upon women's health is comparable to tuberculosis, HIV, heart disease and cancer, and three times greater than the effect of war (Heise et al. 1994). In Victoria, Australia, a health department study found that domestic violence contributes 9 per cent to the total disease burden in Victorian of women aged 15-44, and is responsible for more disease than high blood pressure, smoking or obesity (VicHealth 2004). It has been well documented that women experience significantly higher rates of depression than men and their depression is more likely to be severe and chronic. New research links the prevalence of GBV and sexual violence in particular to the increased burden of depression born by girls and women (Dunn et al. 2012).

The impacts of GBV upon girls and women are mediated by the social structural factors in which GBV takes shape. For example, higher rates of GBV are reported in communities where girls and women face greater levels of structural inequality including a lack of access to education and job opportunities (Bailey and Peterson 1995; Chowdhary and Patel 2010; Yodanis 2004). Failures of law, policy and service provision to respond constructively to GBV have often been identified as a reflection of a sexist 'culture' and entrenched organisational practices and social prejudices (Humphreys 2007; Kelly and Radford 1990; Scutt 1997). However, this paper goes further to argue that these failures are gendered and have gendering effects, much like GBV itself. In interpersonal, social and institutional responses to GBV, victimised girls and women find that their needs are denied and their own responses to victimisation are trivialised and minimised. Such experiences were identified by Linehan (1993) as a form of 'invalidation' and the next section will examine invalidation and GBV in more detail.

\section{The role of invalidation in GBV}

Linehan (1993) developed the concept of invalidation whilst examining the factors that mediated between children sexual abuse and adult mental health. She identified a group of severely impacted women who described growing up in environments in which, while being 
sexually abused, their thoughts, feelings and opinions were chronically dismissed or trivialised. Linehan (1993) called this process 'invalidation', and she theorised that it could exacerbate the impact of abuse by disrupting emotional and cognitive development. Exposure to persistent invalidation has been linked by researchers to the development of personality disorders, depression, eating disorders, alcohol and drug abuse, self-harm and acute psychological distress among women (Krause et al. 2003; Haslam et al. 2008; Jack and Dill 1992; Linehan 1993; Sim et al. 2009).

Linehan (1993) noted that some families constitute particularly invalidating social environments; however, she highlighted how invalidation occurs primarily to girls and women. Her work suggests that being over-ridden, undermined and enduring the imposition of others' views is a common and pervasive experience amongst girls and women in Western culture. This claim corresponds with feminist research on the invalidating responses of the community and medico-legal systems to women victimised by GBV (Bostock et al. 2009; Kelly and Radford 1990; Scutt 1997). These insights have not been combined to place invalidation within its social and political context but this would seem to be a potentially useful approach in understanding the role of invalidation in GBV and gender inequality.

An influential body of theory on crime and violence suggests that it is a method for 'doing gender' (Messerschmidt 1993; Polk 2003; West and Zimmerman 1987) whereby masculinity is constituted and embodied through violent behaviours and displays. However, as Schrock and Shwalbe (2009) point out, the capacity of such acts to display masculinity are linked to their impact on others, insofar as the success of an attempt to claim masculine privilege necessarily rests on eliciting deference or enforcing subordination. From this perspective, GBV is fundamentally a relational phenomenon as the perpetrator seeks to establish and maintain a relation of domination over the victim/s. It would seem that invalidation is an inherent component of this relation, as abusive men draw on 'the power (traditionally conferred on men) of defining people, events and relationships' in order to contest and reshape women's and children's experiences of abuse and violence so that 'his voice and his "truth" seep into women's and children's minds and beings in complex and interlocking ways' (Morris 2009: 417-18).

Research with male offenders has documented the intertwining of invalidation with acts of GBV. Studies of convicted rapists find that, throughout and following the offence, they repeatedly impose their construction of the rape upon their victim and others, insisting that the victim wanted and enjoyed the abuse (Scully 1988; Scully and Marolla 1985a; Scully and Marolla, 1985b). Rape survivor Winkler (1991) recalled how the perpetrator employed language to 'define his life over mine' and his claims that 'you like that' (p. 12) and '[i]t's your fault. I didn't want to hurt you' (p. 13). The literature on the treatment of domestic violence perpetrators has documented pervasive patterns of victim-blaming, minimisation and denial (see Henning and Holdford 2006). Such legitimations express the offender's paradoxical desire to assert potency and mastery while projecting responsibility to their victim.

Invalidation is not only an important psychological component of the act of GBV but it is also a strategy used by perpetrators to deny that the incident took place and hence to minimise the likelihood of disclosure and detection. One participant in a qualitative study of survivors of rape reported that, after a deliberately brutal assault, the rapist sent text messages about their 'great night'. She commented, '[And I thought] oh, well, I must have misinterpreted him. I must be in the wrong here' (Clark and Quadara 2010: 33). Research with survivors of domestic violence and child sexual abuse shows how the perpetrator's retrospective rationalisation or denial of the event delegitimises the experience of the victim and reshapes her understanding of her victimisation (Leahy et al. 2004; Towns and Adams 2009). In the case of child sexual abuse, post hoc invalidation by the perpetrator may disrupt memory encoding and thus inhibit any subsequent recollection of the abuse (Sivers et al. 2002). 
Through strategies of invalidation, the perpetrator attempts to 'other' the girl or woman to herself by crafting an image of her that she does not recognise, thus alienating her from her own identity and experience. This creates an opportunity for him to impose a reconstruction of the event upon the victim that simultaneously reinforces his sense of masculine prestige whilst disrupting her recollection and fragmenting any subsequent narrative of victimisation. However, in the experiences of victims, there is often a continuum of invalidation that persists after the abusive situation or relationship has ended through the reproduction of invalidation in familial, cultural and institutional environments. The following section will focus in particular on institutionalised invalidation by drawing on Habermas' (1984) theory of discourse to conceptualise institutions as 'discursive contexts' that draw attributions of value away from the testimony of girls and women.

\section{The institutional reproduction of invalidation}

The experience of GBV can be understood as inherently invalidating since the thoughts, needs and wants of the victim are eclipsed, even if only momentarily, as the perpetrator enforces her participation within a production of gendered power. In turn, survivors of GBV can and do contest the legitimacy of this imposition and reassert their capacity for self-determination, and much of the energy of feminist movement has come from victims and survivors of sexual abuse, sexual assault and domestic violence. Victim resistance is evident during acts of GBV and through the survivors' subsequent pursuit of justice, wellbeing and acknowledgement of the harms committed against them (Profitt 2000; Taylor and Norma 2012; Ullman and Knight 1993).

However, for many girls and women, the conditions for a robust counter-response to the invalidating qualities of GBV are often absent. Female victims of violent crime appear to experience lower levels of social support than male victims and are more likely to be subject to negative responses from family and friends, which increases the health impacts of violence upon women (Andrews et al. 2003). Such negative responses to female victims emerge from within a cultural context that includes widespread victim-blaming attitudes (Suarez and Gadalla 2010; Taylor and Mouzos 2006) and pro-violence beliefs about male aggression (Indermaur 1996). This serves as a backdrop to institutional arrangements that are not only unresponsive to the needs of survivors of GBV but may forcefully reproduce patterns of silencing and invalidation (Davidson and McNamara 1999; Kelly and Radford 1990; Lavis et al. 2005).

Habermas (1990: 31) has emphasised the importance of mutual recognition as one of the 'general and necessary conditions for the validity of symbolic expressions and achievements'. His work on discourse ethics (see Habermas 1984) has focused on the way in which meaning coheres for social actors through the consensus-making properties of communication and interaction, giving rise to a sense of belonging and relatedness and providing the basis for collective action. However, this process of consensus-making takes place against a shared and implicit social backdrop that feminist theorists argue are structured by preflexive sexist norms and values (Cohen 2002; Fraser 2002; Meehan 2002). Hence implicit understandings of gender and sexuality have a pervasive influence over institutionalised processes that assess the validity of the claims of victimised girls and women, such as psychiatric assessments or legal trials. These processes are shaped by cultural mythologies about femininity that persistently undermine female testimony and draw value attributions away from girls and women, but they are legitimised by medico-legal rationality in such a way as to be 'sealed off from critique' (Cohen 2002: 68).

If the possibility of dialogue between presumptive equals is the basis of public and political life, as Habermas (1984) suggests, then the myriad of ways in which women's speech is rendered indeterminate and turned against them underscores the political dimensions of invalidation. Legal responses to GBV often employ the language of perpetrators of GBV, and this vocabulary is 
used in a similar fashion in order to over-write the victim's own experiences. As a result, complaints of rape are often re-narrated in court in ways that conflate rape with romance (Philadelphoff-Puren 2005) and force women to contend with masculine fantasies of flight and seduction (Young 1998). In a study of advocates for battered women, one advocate described 'this absolutely eerie feeling that these guys were getting together and deciding what to say or do. The people in the system were saying a lot of the same things that the men [perpetrators] were saying ...' (Pence and Shepard 1999: 8). Feminist efforts at law reform have yielded disappointing results, as formal measures to improve the treatment of victims and increase prosecution rates have been stymied by the 'resiliency of cultural mythologies about women and about sexuality' (Stubbs 2003: 23).

Just as the offender can draw on the power of invalidation in the commission of GBV, he can also turn it to his advantage once the offence has been reported. For example, a counter-claim by a perpetrator can easily disrupt a victim's claim in relation to the injustice of his actions by, in turn, reframing her allegation as an act of aggression against him. Discourses of 'false memories' and 'parental alienation' are regularly employed in criminal and civil courts by men accused of abusing children and women to characterise themselves as the victims of false allegations (Faller 1998; Lisak 2010; Whitfield 2001). The perpetrator's efforts to reposition himself as the innocent or naïve victim of an unfounded allegation is frequently successful in both social and institutional settings, particularly where he embodies valued masculine traits (for example sporting prowess; see Philadelphoff-Puren 2004) and where the woman or girl can be characterised according to pejorative stereotypes in which femininity is construed in terms of hysteria and deceitfulness (Gaarder 2000; Stevenson 2000). Recent increases in dual arrests for domestic violence is a poignant example of men's capacity to claim victimhood when accused of GBV (Muftić et al. 2007).

The ways in which meaning coheres around girls' and women's disclosures of GBV not only tends to invalidate them, but it also reframes them in ways that supports the legitimising ideologies of the gender order. As the following section will argue, the vulnerability of victims of GBV to invalidation across virtually all contexts of interaction (whether interpersonal or institutional) points to the ideological complex of gender, power and violence. This suggests that invalidation is a core mechanism through which feminine subordination is inscribed, lived and experienced and hence it is a crucial, although under-recognised, support system for masculine domination.

\section{Invalidation and ideology}

Invalidation perpetuates gendered inequality through simultaneous and linked operations: not only does it symbolically deny the victim's agency and subjectivity during the experience of GBV but in the aftermath it can also result in the withholding of access to vital emotional support as well as health and justice services, leading to the variety of deficits (psychological, emotional, economic, social) that can accrue in the lives of girls and women due to these interlocking processes. Invalidation is therefore not only an effect of gendered inequality but it also recreates the social conditions for it. Althusser (1984: 1) paraphrases Marx to say that 'every child knows that a social formation that did not reproduce the conditions of production at the same time as it produced, would not last a year'. Similarly, invalidation is a product of the social formation of masculine domination that also reproduces masculine domination. As this section of the paper will discuss, invalidation not only produces alterations in women's mental and physical health and social status but it also holds them responsible for these changes.

According to Althusser (1984), ideology is not imposed upon an abstract, pre-ideological subject but rather the subject is 'always-already interpellated' in that it is ideology that constitutes the subject and forms subjectivity. Individuals acquire their identity within social conditions that are implicitly structured by ideology and hence in their social practice they come to embody 
ideological truths and roles. When the individual is interpellated or 'hailed' in ways that invoke the subject's position within ideological structures, the subject recognises herself in relation to that structure. A way of being and feeling is called forth that is both impersonal and intimate in that interpellation positions the subject in relation to an ideology that is simultaneously externally evident and internally familiar.

GBV is the paradigmatic interpellating operation of masculine domination in that it 'hails' women and girls to recognise themselves as subordinate subjects, if not solely as objects of abuse and coercion. It is through the effacement of individual agency by the ideological truth of feminine subordination and its enforcement through coercion and abuse that the perpetrator can craft the corresponding experience of domination through which masculinity is (momentarily) validated and lived. The victim is necessarily possessed of her own identity but the repetitious nature of GBV constitutes a system of interpellation that can disrupt the maintenance of an autonomous and self-affirming sense of selfhood. The effectiveness of this process is amplified by the subtle and pervasive operations of gendered inequity in everyday life, which incessantly confirms and re-activates the logic of masculine domination (Bourdieu 2001).

Repeated acts of violence 'hail' the victim to recognise her subordinate position within the gender order, and thus the logic of masculine domination becomes increasingly intrusive as its violence invokes within the victim the imaginary representations of masculine domination that she has internalised. Zizek (1996) notes that trauma is never a purely 'external' intrusion since its symbolic impact arises from its ideological resonance within the victim. 'What we have in mind here is by no means that standard male chauvinist "wisdom" according to which, say, a woman silently enjoys being raped, but, on the contrary, the fact that the impact of violence is all the more horrifying, the more it stirs up some fantasmatic kernel ... Symbolic fiction therefore always intermingles with "real" violence' (Zizek 1996: 16). The activation of the 'fantasmatic kernel' of masculine domination by GBV enacts a symbolic violence upon the victim's sense of self, autonomy and agency that is deeply and profoundly invalidating, situating her as the natural inferior to her perpetrator and challenging the authenticity of her agency and subjectivity.

Irigaray (1985) suggests that the concept of the 'female subject' is an oxymoron in the prevailing symbolic order in which the 'feminine' features perpetually as 'other' and never as 'subject'. Girls and women face the dilemma that they are just as agentic as boys and men but they are persistently 'hailed' to recognise themselves as passive objects to be acted upon by others, not as subjects. Over time they are socialised to suppress or silence those dimensions of subjectivity that interfere with their objectified status within the gender order. This process begins early even in the absence of GBV. Brown's and Gilligan's (1992) research with girls and young women suggests that female pathways from childhood to adolescence and adulthood are often marked by 'an inner division as girls come to a place where they feel they cannot say or feel or know what they have experienced' (p. 4).

However it is in the commission and aftermath of GBV that invalidation emerges as a pronounced feature of girls' and women's experience. This is particularly the case where girls and women actively resist their victimisation by, for example, pursuing formal redress in the justice system or seeking support from health and welfare services. The traditionally masculine professions of medicine and the law serve as the gatekeepers of social legitimacy for claims of GBV, along with the 'psy' disciplines whose credibility is based, to a significant degree, on a strategic alignment with the medical sciences and the criminal justice system. The interwoven procedures, rationales and discourses of these professions transfigure and rearrange testimony and evidence of GBV according to cultural logics of gender and power. In this process, the representations put forth by the victim of her experience, whether it is her testimony or her psychological symptoms of abuse (which can be understood as symbolic representations; see 
Bronfen 1998), are rerouted into a complex circuitry of bureaucratic and scientific rationality, only to be presented back to her in a form that 'hails' her in ways that are perturbingly similar to the interpellating qualities of her original victimisation.

In effect, the energy that comes from girl's and women's resistance to female subordination is persistently siphoned off by these ideological apparatuses and reworked into symbolic representations that affirm the legitimacy of masculine domination and draw victimised women and girls even deeper into the web of interpellation. As their needs escalate as a result of their victimisation, these not only go unrecognised and unmet in an invalidating environment but they are overwritten by a pervasive code that holds the victim accountable for her own distress. Culturally, the symptoms of GBV (such as mood disorders, emotional disturbances and difficulties with trust and interpersonal relations) are not linked to their source but rather they are understood to be part of the 'feminine condition' (Warner 1996). The social reception to girls' and women's testimony of GBV is characterised by patterns of disbelief and victim blaming that conflate their distress with the hysteria and neurosis that is associated with femininity as a whole (Campbell 2003). As a form of interpellation, GBV creates both gendered subjects and the ideological confines for gendered subjectivity.

\section{Conclusion}

This paper has shown that invalidation is a powerful tool in the perpetuation of gendered inequality that can be drawn on strategically by men in order to make GBV possible and to assign the responsibility for GBV and its psychological harms to girls and women. Violence and its effects are revealed as central to the code of gender, and the paper has emphasised in particular the impacts of GBV across the lifespan of women through its linkages with ill-health as well as the wide-ranging cultural significance of these impacts. The ways that power operates through the gender order not only shapes language and symbols but it 'also constructs the meaning of bodies and operates upon them' (Cohen 2002: 70). The dialectic between GBV and invalidation is a powerful means by which masculine domination exerts a material effect upon the bodies and minds of girls and women.

Invalidation is an ideological process that disrupts the reciprocity and mutuality of the intersubjective processes that are fundamental to the assertion of agency and selfhood, conferring upon women and girls a sense of their subordinate social position in a gendered society. This experience is more intensive for some girls and women than for others; however, it seems that GBV is an interpellating experience that activates the symbolic power of masculine domination in profoundly disenabling ways. Exposure to pervasive invalidation leaves girls and women differentially vulnerable to victimisation and mental illness but, in the aftermath of abuse and violence, it can precipitate an overall self-negation that embeds gender inequity through a further diminution in mental and physical health. GBV not only produces particular forms of feminine subjectivity but it provides the raw materials for the legitimisation of masculine domination, as women's responses and resistance to GBV are reshaped and reinterpreted within ideological apparatuses such as medicine and the law.

By understanding the multiple operations of invalidation, we can conceptualise the ways in which perpetrators, families, communities, institutions and systems collectively compromise the health and life outcomes of girls and women and differentially expose them to the harms of GBV across the lifespan. This is a perspective that can inform a range of responses from education and prevention strategies through to treatment, as well as the processes of the criminal justice system, police and other agencies tasked to respond to GBV. This paper foregrounds the importance of addressing girls' and women's qualitative experiences of interventions and services that are tasked to respond to GBV. Remaining mindful of the role of invalidation in GBV and gendered inequality more broadly, and ensuring that validating 
responses are embedded within service and system contexts, not only supports girls and women to seek help and provide testimony but also directly opposes the self-silencing and vulnerability produced by invalidation. By fostering a shared culture of validation across the multiple agencies and systems that come into contact with survivors of GBV, it may be possible to create communicative contexts in which girls and women are empowered to enter into validating speech acts which in turn can foster resiliency.

However, such speech acts must have purchase politically as well as personally in order to address the totality of invalidation. The validation of the speech of girls and women for solely therapeutic purposes might deliver beneficial outcomes to individuals and their families or communities but leave untouched the ways in which cultural norms of masculine dominance have been institutionalised within politics, law and medicine. The systemic invalidation of girls' and women's validity claims provides an enabling social environment for GBV whilst ideological apparatuses reconstitute the distress of victimised girls and women into the legitimising discourses of masculine domination. Validation is a truly moral and political imperative since it serves as the fundamental precondition for the development of stable and coherent subjectivities which, in turn, enable resiliency, self-representation through testimony, and the assertion and exercise of civil and political rights.

Correspondence: Michael Salter, Lecturer in Criminology, School of Sociology and Criminology, University of Western Sydney, Penrith NSW 2751, Australia. Email: michael.salter@uws.edu.au

\section{References}

Althusser L (1984) Ideology and ideological state apparatuses. Essays on Ideology. London: Verso.

Andrews B, Brewin CR and Rose S (2003) Gender, social support, and PTSD in victims of violent crime. Journal of Traumatic Stress 16(4): 421-427.

Bailey WC and Peterson RD (1995) Gender inequality and violence against women: The case of murder. In Hagan J and Peterson RD (eds) Crime and Inequality. Stanford: Stanford University Press: 174-205.

Bostock J, Plumpton M and Pratt R (2009) Domestic violence against women: Understanding social processes and women's experiences. Journal of Community \& Applied Social Psychology 19: 95-110.

Bourdieu P (2001) Masculine Domination. Oxford: Polity Press.

Bronfen E (1998) The Knotted Subject: Hysteria and Its Discontents. Princeton: Princeton University Press.

Brown LM and Gilligan C (1992) Meeting at the Crossroads: Women's Psychology and Girls' Development. Cambridge and London: Harvard University Press.

Cambell R, Wasco SM, Ahrens CE, Sefl T and Barnes HE (2001) Preventing the 'second rape': Rape survivors experiences with community service providers. Journal of Interpersonal Violence 16(12): 1239-1259.

Campbell S (2003) Relational Remembering: Rethinking the Memory Wars. Oxford: Rowman and Littlefield Publishers, Inc.

Chowdhary N and Patel V (2010) Gender-based violence and mental health. In Kohen D (ed) Oxford Textbook of Women and Mental Health. Oxford: Oxford University Press: 7-16

Clark H and Quadara A (2010) Insights into Sexual Assault Perpetration: Giving Voice to Victims/Survivors' Knowledge. Melbourne: Australian Institute of Family Studies.

Cohen J (2002) Critical social theory and feminist critiques: The debate with Jurgen Habermas. In Sheehan J (ed) Feminists Read Habermas: Gendering the Subject of Discourse. New York and London: Routledge: 57-90. 
Coker AL, Smith PH, Thompson MP, Mckeon RE, Bethea L and Davis KE (2002) Social support protects against the negative effects of partner violence on mental health. Journal of Women's Health \& Gender Based-Medicine 11(5): 465-476.

Davidson J and Mcnamara L (1999) Systems that silence: Lifting the lid on psychiatric institutional abuse. In Breckenridge J and Laing L (eds) Challenging Silence: Innovative Responses to Sexual and Domestic Violence. St Leonards: Allen and Unwin: 86-102.

Dunn EC, Gilman SE, Willett JB, Slopen NB and Molnar BE (2012) The impact of exposure to interpersonal violence on gender differences in adolescent-onset major depression: Results from the National Comorbidity Survey Replication (NCS-R). Depression and Anxiety 29(5): 392-399.

Evans SE, Davies C and Dilillo D (2008) Exposure to domestic violence: A meta-analysis of child and adolescent outcomes. Aggression and Violent Behavior 13: 131-140.

Faller KC (1998) The parental alienation syndrome: What is it and what data support it? Child Maltreatment 3(2): 100-115.

Fraser N (2002) What's critical about critical theory? The case of Habermas and gender. In Rasmussen D and Swindal J (eds) Jurgen Habermas: Volume III. London, Thousand Oaks \& New Delhi: Sage: 55-84.

Gaarder E (2000) Gender politics: The focus on women in the memory debates. Journal of Child Sexual Abuse 9(1): 91-106.

García-Moreno C, Jansen H, Ellsberg M, Heise L and Watts C (2005) WHO Multi-country Study on Women's Health and Domestic Violence Against Women. Initial Results on Prevalence, Health Outcomes and Women's Responses. Geneva: World Health Organisation.

Habermas J (1984) The Theory of Communicative Action. London: Heinemann Educational.

Habermas J (1990) Moral Consciousness and Communicative Action. Cambridge, MA: MIT Press.

Haslam M, Mountford V, Meyer C and Waller G (2008) Invalidating childhood environments in anorexia and bulimia nervosa. Eating Behaviors 9: 313-318.

Heise L, Pitanguy J and Germain A (1994) Violence Against Women: The Hidden Health Burden. Worldbank Discussion Papers, No. 255. Washington DC: World Bank.

Heise, L, Ellsberg M and Gottmoeller M (2002) A global overview of gender-based violence. International Journal of Gynaecology and Obstetrics: The Official Organ of the International Federation of Gynaecology and Obstetrics 78: S5-S14.

Henning K and Holdford R (2006) Minimization, denial, and victim blaming by batterers. Criminal Justice and Behavior 33(1): 110-130.

Humphreys C (2007) A health inequalities perspective on violence against women. Health \& Social Care in the Community 15(2): 120-127.

Indermaur D (1996) Perceptions of violence. Psychiatry, Psychology \& Law 3(2): 129-141.

Irigaray L (1985) The Sex Which is Not On. Ithaca, NY: Cornell University Press.

Jack DC and Dill D (1992) The silencing the self scale: Schemas of intimacy associated with depression in Women. Psychology of Women Quarterly 16(1): 97-106.

Johnson MP (2008) A Typology of Domestic Violence: Intimate Terrorism, Violent Resistance and Situational Couple Violence. Lebanon, NH: Northeastern University Press.

Kaukinen C and Demaris A (2009) Sexual assault and current mental health: The role of helpseeking and police response. Violence Against Women 15(11): 1331-1357.

Kelly L (1988) Surviving Sexual Violence. Oxford: Blackwell.

Kelly L and Radford J (1990) 'Nothing really happened': The invalidation of women's experiences of sexual violence. Critical Social Policy 10: 39-53.

Krause ED, Mendelson T and Lynch TR (2003) Childhood emotional invalidation and adult psychological distress: The mediating role of emotional inhibition. Child Abuse \& Neglect 27: 199-213.

Lavis V, Horrocks C, Kelly N and Barker V (2005) Domestic violence and health care: Opening pandora's box - challenges and dilemmas. Feminism and Psychology 15(4): 441-460.

Leahy T, Pretty G and Tenenbaum G (2004) Perpetrator methodology as a predictor of traumatic symptomatology in adult survivors of childhood sexual abuse. Journal of Interpersonal Violence 19(5): 521-540. 
Linehan M (1993) Cognitive Behavioral Treatment of Borderline Personality Disorder. New York: Guilford Press.

Lisak D (2010) Behind the torment of rape victims lies a dark fear: Reply to the commentaries. Violence Against Women 16(12): 1372-1374.

Meehan J (2002) Feminism and Habermas' discourse ethics. In Rasmussen D and Swindal J (eds) Jurgen Habermas: Volume III. London, Thousand Oaks \& New Delhi: Sage: 91-103.

Messerschmidt JW (1993) Masculinities and Crime: Critique and Reconceptualization of Theory. Lanham, MA: Rowman and Littlefield Publishers.

Morris A (2009) Gendered dynamics of abuse and violence in families: Considering the abusive household gender regime. Child Abuse Review 18(6): 414-427.

Muftić LR, Bouffard JA and Bouffard LA (2007) An exploratory study of women arrested for intimate partner violence. Journal of Interpersonal Violence 22(6): 753-774.

Nakray J (ed) (2013) Gender-based Violence and Public Health: International Perspectives on Budgets and Policies. London and New York: Routledge.

Pence EL and Shepard MF (1999) Introduction. In Shepard MF and Pence EL (eds) Coordinating Community Responses to Domestic Violence: Lessons from Duluth and Beyond. California, London and New Delhi: Sage: 3-24.

Philadelphoff-Puren N (2004) Dereliction: Women, rape and football. Australian Feminist Law Journal 21: 35-51.

Philadelphoff-Puren N (2005) Contextualising consent: The problem of rape and romance. Australian Feminist Studies 20(46): 31-42.

Polk K (2003) Masculinities, femininities and homicide: Competing explanations for male violence. In Schwartz M and Hatty SE (eds) Controversies in Critical Criminology. Cincinnati: Anderson: 133-145.

Profitt NJ (2000) Women Survivors, Psychological Trauma and the Politics of Resistance. Binghamton, NY: Haworth.

Schrock D and Schwalbe M (2009) Men, masculinity and manhood acts. Annual Review of Sociology 35: 277-295.

Scully D and Marolla J (1985a) Convicted rapists' vocabulary of motive: Excuses and motivations. Social Problems 31(5): 530-544.

Scully D and Marolla J (1985b) 'Riding the bull at Gilley's': Convicted rapists describe the rewards of rape. Social Problems 32(3): 251-263.

Scully D (1988) Convicted rapists' perceptions of self and victim. Gender \& Society 2(2): 200213.

Scutt J (1997) The Incredible Woman: Power and Sexual Politics (Vol 1). Melbourne: Artemis Publishing.

Sim L, Adrian M, Zeman J, Cassano, M and Friedrich WN (2009) Adolescent deliberate self-harm: Linkages to emotion regulation and family emotional climate. Journal of Research on Adolescence 19(1): 75-91.

Sivers H, Schooler J and Freyd J (2002) Recovered memories. In Rachamandran VS (ed) Encyclopedia of the Human Brain. San Diego, CA: Academic Press: 169-184.

Stark E (2007) Coercive Control: How Men Entrap Women in Personal Life. New York: Oxford University Press.

Stevenson K (2000) Unequivocal victims: The historical roots of the mystification of the female complainant in rape cases. Feminist Legal Studies 8(3): 343-366.

Stubbs J (2003) Sexual assault, criminal justice and law and order. Women Against Violence: An Australian Feminist Journal 14: 14-26.

Suarez E and Gadalla TM (2010) Stop blaming the victim: A meta-analysis on rape myths. Journal of Interpersonal Violence 25(11): 2010-2035.

Taylor N and Mouzos J (2006) Community Attitudes to Violence Against Women Survey 2006: A Full Technical Report. Canberra: Australian Institute of Criminology.

Taylor SC and Norma C (2012) The "symbolic protest" behind women's reporting of sexual assault crime to police. Feminist Criminology 7(1): 24-47. 
Towns AJ and Adams PJ (2009) Staying quiet or getting out: Some ideological dilemmas faced by women who experience violence from male partners. British Journal of Social Psychology 48(4): 735-754.

Ullman SE (2003) Social reactions to child sexual abuse disclosures: A critical review. Journal of Child Sexual Abuse 12(1): 89-121.

Ullman SE and Knight RA (1993) The efficacy of women's resistance strategies in rape situations. Psychology of Women Quarterly 17(1): 23-38.

VicHealth (2004) The Health Costs of Violence: Measuring the Burden of Disease Caused by Intimate Partner Violence [Online]. Melbourne: VicHealth.

Warner S (1996) Constructing femininity: Models of child sexual abuse and the production of 'woman'. In Burman E (ed) Challenging Women: Psychology's Exclusions, Feminist Possibilities. Ballmore and New York: Open University Press: 36-53.

West C and Zimmerman DH (1987) Doing gender. Gender \& Society 1(2): 125-151.

Whitfield CL (2001) The 'false memory' defense: Using disinformation and junk science in and out of court. The Journal of Child Sexual Abuse 9(3-4): 53-78.

Winkler C (1991) Rape as social murder. Anthropology Today 7(3): 12-14.

Yodanis CL (2004) Gender inequality, violence against women, and fear. Journal of Interpersonal Violence 19(6): 655-675.

Young A (1998) The waste land of the law, the worldess song of the rape victim. Melbourne University Law Review 22: 442-465.

Zizek S (1996) Invisible ideology: Political violence between fiction and fantasy. Journal of Political Ideologies 1(1): 15-32. 